\title{
Olympiad potential for identifying mathematical giftedness in elementary schoolers
}

\author{
S.P. Zubova ${ }^{1 *}$, L.V. Lysogorova ${ }^{1}, N . G$. Kochetova ${ }^{1}$, and T.V. Fedorova ${ }^{1}$ \\ ${ }^{1}$ Samara State University of Social Sciences and Education, Faculty of Primary Education, Primary \\ Education Department, Samara, Russia
}

\begin{abstract}
The purpose of this article is to demonstrate the possibilities of identifying the mathematical giftedness in elementary schoolers with the help of Olympiad problems. For this, the authors clarify the concept of "mathematical giftedness", show the relationship between the concepts of "mathematical giftedness" and "mathematical abilities", and indicate the most significant abilities of elementary schoolers from the set of mathematical giftedness. The role of mathematical Olympiads in identifying mathematically gifted elementary schoolers is substantiated. This role consists in creating situations where the participants of the Olympiad are forced to make mental efforts to perform the following actions: analysis of a problem situation to identify essential relationships, modeling a new way of action to solve the proposed problem, combining available methods of action to apply in a new situation in limited time. The criteria for compiling Olympiad tasks for identifying mathematically gifted students are formulated, the most important of which is the clear focus of each task on demonstrating a mathematical ability of a certain type, as well as the selection of the mathematical content of the Olympiad problems strictly from the elementary course of mathematics. The problems of one Olympiad should be based on the content of different sections of the elementary mathematics course. The examples of the Olympiad problems based on the content of the elementary mathematics course are provided and the substantiation of their role in demonstrating the mathematical abilities of the Olympiad participant in solving them is given. The results of observing the educational achievements of students (during their entire stay at school) who showed mathematical abilities at the Olympiads are provided as well as the prospects and certain difficulties of further research on ways to solve the problem.
\end{abstract}

Keywords: Olympiad problems, mathematical giftedness, elementary schoolers.

\section{Introduction}

It is hard to disagree with the statement that every child is unique and has abilities. What qualities essentially distinguish gifted children, including those with abilities in mathematics? How should their activities and training be organized? These and many other questions

\footnotetext{
*Corresponding author: zubova@pgsga.ru
} 
regarding the identification and development of talent, mathematical giftedness, children's mathematical abilities are of interest to both psychologists and practicing teachers. These features must be identified as early as possible to structure and correct the further educational process. Olympiads for junior schoolchildren, including mathematical ones, have great potential for revealing giftedness. At the same time, this potential is often not used, the results of mathematical Olympiads are not analyzed by the teacher and are not taken into account when further building the students' educational trajectories. All this makes it relevant to determine the possibilities of the Olympiads for identifying giftedness, in particular, in mathematics, for elementary schoolers.

\section{Methods}

This article presents the results of observations of elementary schoolers participating in mathematical Olympiads over 24 years. The problems for school and city-level Olympiads in mathematics for elementary schoolers were composed in such a way that, while completing a math problem, the student had to use certain intellectual techniques - comparison, analysis, analogy, modeling, etc., as well as show out-of-the-box and flexible thinking. The results of the Olympiads were analyzed, the students were identified who suggested the correct solutions, and then, taking into account the results of the analysis, recommendations were developed for building individual trajectories and such students were observed until school graduation (11 grades).

The compilation of the Olympiad problems was preceded by a theoretical study to identify the essence of the concept of "mathematical giftedness". We should note that some authors understand giftedness as the initial level of development of abilities, which are different for each child and depend on natural inclinations and other individual psychological characteristics [1]. If giftedness is accompanied by an inclination towards a certain activity and the child seeks to constantly perform this activity and achieves some success, then it can be argued that the child has a talent.

Therefore, the terms "capable", "gifted", "talented" reflect the degree to which abilities are expressed [2]. Ability and giftedness are certain steps to talent.

One of the types of giftedness is "mathematical giftedness", however, there is still no consensus on the essence and structure of mathematical giftedness.

The core of mathematical giftedness, according to V.A. Testov, is mathematical abilities, that is, the ability to successfully solve mathematical problems [3].

A similar interpretation of mathematical abilities is offered by V.A. Krutetskii. The scholar emphasized that the possession of such abilities is manifested in a relatively quick, easy, and deep mastery of mathematical concepts and methods [4].

By developing the mathematical abilities in elementary schoolers, one thereby develops their mathematical giftedness. Therefore, teaching mathematics to elementary schoolers should be structured in such a way as to create conditions for the targeted development of mathematical abilities as the core of mathematical giftedness [5-7]. It is clear that not all students have exactly this kind of abilities, therefore, it is necessary first to identify such students to build individual educational trajectories. To this end, we hold mathematic Olympiads of different levels for elementary schoolers.

Olympiads in this case are individual, that is, each participant is responsible only for their personal results. It is in this case that an incentive is created to make mental efforts to become a winner, the fear of getting a bad mark disappears replaced by the desire to overcome difficulties.

Olympiad problems are mostly unorthodox, requiring the manifestation of the ability to apply existing methods of action in an unfamiliar situation, the use of new combinations of 
known techniques, originality, flexibility, and rationality of thinking, that is, those qualities that are inherent in mathematically gifted students.

At the same time, to more accurately judge the presence of mathematical giftedness in a student - an Olympiad participant, it is necessary to compose the Olympiad problems in such a way that the participant demonstrates, if possible, the maximum number of different types of mathematical abilities.

Analyses of the structure of mathematical abilities presented in the studies of various scientists (A.V. Beloshistaya, V.A. Krutetskii, V.A. Testov, I.S. Yakimanskaya, etc.) [3, 4, 8-10] allowed us to identify the following basic mathematical abilities that should be developed starting from elementary school age or earlier:

- the ability to analyze, compare, draw an analogy;

- the ability to obtain empirical and, in some cases, theoretical generalizations;

- the ability to encode and recode information, build and transform models (sign, graphic, verbal) for their further research;

- the ability to find different ways to solve a problem and choose rational ones;

- the ability to think "in reverse".

All these abilities are interrelated and form the basis for the development of other mathematical abilities.

Based on the identified basic mathematical abilities of elementary schoolers, we have developed the mathematic Olympiad tasks, taking into account the following requirements.

- All assignments are based on mathematical content strictly within the framework of the elementary mathematics curriculum. We do not recommend borrowing standard problems from the basic school course as Olympiad problems.

- The completion of each task involves the use of a certain component from the set of mathematical abilities.

- Each assignment is based on the content of a section of the elementary mathematics course.

Here are examples of some problems.

1. People of the Fairy Tale Land use a special, fairytale table of units of length. It is similar to the table of units of length that we use, in that each next larger unit in the table contains the same number of units of the previous, smaller measure of length.

1 click $=\ldots$ clyack $=\ldots$. cluck $=\ldots .$. cleck $=256$ clack

Clue. The proportion of units of length in Russia: $1 \mathrm{~m}=10 \mathrm{dm}=100 \mathrm{sm}=1000 \mathrm{~mm}$.

This problem on the content of the "Units" section makes it possible to reveal the student's ability to draw an analogy (or a formed generalized concept of a unit).

2. There is an equation on the blackboard $\odot:(7-x)+11=12$, but one number has been accidentally erased (labeled with a smiley face). What number could this be? Find possible solutions.

Here the participant is required to show the flexibility of thinking (the ability to think "in reverse"). If the student gives several solutions, then it can be argued that the variability of thinking is also manifested.

The section of the elementary course of mathematics is algebraic material; the mathematical skill is solving an equation based on the relationship between components and the result of actions.

3. People in Fairy Tale Land use shapes instead of numbers. Problem. Matroskin the Cat should pour milk into jugs. Matroskin knows that for $\boldsymbol{\Delta}$ liters of milk one needs $\mathbf{\square}$ jugs. How many jugs does Matroskin need for liters of milk? The answer should be $\bullet$ jugs. Put together equations that are the solutions to this problem if it is inverted. Find all solutions.

To complete this task, one must demonstrate the ability to compose and transform sign models, master a generalized method for solving the problem of finding the fourth 
proportional (a typical problem with proportional values, studied in the second grade). To compose an inverted problem requires the ability to think in reverse, enumerate all the variants of equations to solve the inverse problem - variability of thinking. These problems, presented in a generalized form, force the student to think beyond specific data.

The section of the elementary course of mathematics here is arithmetic plot-based problems.

4. Detective Severtsev is looking for the driver who was in an accident and fled in his car. The witnesses remembered some details. Thus, the detective managed to establish the following:

- The vehicle license plate is a four-digit number.

- The difference between the second and third digits of the license plate is 4 .

- If you add up the numbers that are indicated by the first and fourth digits of the license plate, you get the number 7 .

- There are no identical digits on the license plate.

- How many license plate options does Detective Severtsev have to check?

- This task presupposes knowing how to operate a large amount of information and find different ways of solving the problem.

The section of the elementary course of mathematics - numbering multidigit numbers.

After the Olympiad is held, the results are analyzed, based on which recommendations are drawn up for building an individual educational trajectory for winners, medallists, or participants who proposed original solutions to individual problems.

\section{Results}

Throughout the study, there was (and is) observation of several medalists who were students of the State Budgetary General Education Institution Gymnasium No. 1, Municipal Budgetary Educational Institutions - Schools No. 176, 53, 124 in Samara (by now 14 people have completed their school education). For each of them, individual educational trajectories were built (recommendations were given on participation in other Olympiads, courses were held by teachers of the Faculty of Primary Education, within which tasks were performed aimed at further developing mathematical abilities). It should be noted that six people out of 14 had a "B" mark in mathematics in the fourth grade. Consequently, there was a possibility that if the students did not participate in the Olympiad, this would negatively affect the structure of their educational trajectories and make it difficult to achieve the educational results that they had. All 14 people received scores above 75 at the Unified State Examination in Mathematics and entered universities, having fulfilled their desires. Out of 14 students, nine entered universities based on the results of the Olympiads. Thus, the identification of mathematically gifted students already at the primary level of education made it possible to further facilitate the achievement of higher results in the development of mathematical giftedness.

\section{Discussion}

Thus, mathematical Olympiads allow one to identify mathematically gifted students if the Olympiad tasks are compiled according to the above requirements. As many students as possible should participate in the Olympiads of different levels: all students at the intra-class or intra-school stage, and winners or medalists of lower levels of the Olympiads at the district, city, regional, etc. levels. This makes it possible to identify such mathematically gifted students who have not yet managed to prove themselves in the classroom and due to, for example, certain personal qualities or external conditions. 


\section{Conclusion}

All in all, we managed to substantiate the potential of mathematical Olympiads in identifying mathematically gifted students even at the early stages of learning, which, in turn, makes it possible to build an individual educational trajectory for more intensive and less costly development of students [11]. At the same time, the research has prospects: first, there are still no clear criteria for identifying mathematically gifted elementary schoolers among those who have subject knowledge and methods of action within the curriculum. Perhaps this is because mathematical abilities can manifest themselves only on a specific content [12-14]. The age-related feature of elementary schoolers is the presence of mechanical memory which allows them to memorize many small ways of action. Therefore, the completion of ordinary tasks is often not difficult. Due to the small amount of content in the elementary mathematics course, many tasks are repeated, becoming reproductive for elementary schoolers. When solving them, memory is mainly involved. Therefore, there is an urgency to the problem of developing criteria for evaluating the selection of problems for identifying mathematical giftedness. The solution to this problem, on the one hand, would be heuristic, on the other hand, would not go beyond the content of the initial course in mathematics. Second, although the results show regularity, a confirmation is required using a more representative sample. However, such confirmation presents an objective difficulty because a mathematically gifted child is not yet such a frequent phenomenon $[15,16]$. Therefore, the prospect of our research is to develop clear criteria for identifying mathematically gifted elementary schoolers, disseminate the experience of observing mathematically gifted primary schoolchildren, and supplement the system of Olympiad problems with types that require children to demonstrate each type of mathematical ability.

\section{References}

1. L.N. Vakhrusheva, Scientific and Methodological Digital Journal "Kontsept", S27, 1115 (2015)

2. A.I. Savenkov, Odarennye deti: osobennosti psikhicheskogo razvitiya [Gifted children: features of mental development] (Prosveshcheniye, Moscow, 2006)

3. V.A. Testov, Perspektivy Nauki i Obrazovaniya [Science and Education Perspectives], 6(12), 60-67 (2014)

4. V.A. Krutetskii, Psikhologiya matematicheskikh sposobnostei shkolnikov [The psychology of mathematical abilities in schoolchildren], 380-390, 397 (Prosveschenie, Moscow, 1968)

5. M. Stolte, E.H. Kroesbergen, J. E.H. Van Luit, Personality and Individual Differences, 142, 196-201 (2019). https://doi.org/10.1016/j.paid.2018.08.024.

6. I. Cichy, M. Kaczmarczyk, S. Wawrzyniak, A. Kruszwicka, T. Przybyla, M.

Klichowski, A. Rokita, Frontiers in Psychology, 11 (2020).

https://doi.org/10.3389/fpsyg.2020.02194

7. V.V. Utemov, EURASIA Journal of Mathematics, Science and Technology Education, 13(8), 4351-4362 (2017). https://doi.org/10.12973/eurasia.2017.00931a

8. A.V. Beloshistaya, Razvitie matematicheskikh sposobnostei doshkolnikov [Developing mathematical abilities in preschoolers] (Vlados, Moscow, 2004)

9. I.S. Yakimanskaya, Lichnostno-orientirovannoe obuchenie v sovremennoi shkole [Personality-oriented learning in the modern school] (Sentiabr, Moscow, 2014)

10. B.M. Teplov, Problemy individualnykh razlichii [The problems of individual differences] (Nauka, Moscow, 1961) 
11. V. Krcov, S. Portesova, H. Cigler, Ceskoslovenska Psychologie, 61(1), 3-15 (2017)

12. H. Harty, D.M. Adkins, R.D. Sherwood, The Journal of Educational Research, 77(6), 337-342 (1984). https://doi.org/10.1080/00220671.1984.10885552

13. H.E. Wilson, Journal for the Education of the Gifted, 38(4), 377-404 (2015). https://doi.org/10.1177/0162353215607323

14. D. Lubinski, L.G. Humphreys, Intelligence, 14(3), 327-355 (1990). https://doi.org/10.1016/0160-2896(90)90022-1

15. A. Craft, British Journal of Educational Studies, 51(2), 113-127 (2003). https://doi.org/10.1111/1467-8527.t01-1-00229

16. G. Bojorque, N. Gonzales, N. Wijns et al., Eur J Psychol Educ (2020). https://doi.org/10.1007/s10212-020-00510-4 